\title{
A course/laboratory in Computer Integrated Manufacturing system as an integral part of a Mechanical Engineering Technology program
}

\author{
Mohammad S. Davoud, Ph.D., P.E. \\ Georgia Southern University
}

Session 3247

\section{Introduction}

Manufacturers are increasingly automating their production lines with Computer Integrated Manufacturing (CIM) systems in order to stay competitive in the world market. The trend among manufacturers today is to produce smaller batches of more varied products. Without CIM automation, this trend would result in higher costs associated with increased setup time and additional labor. There are, however, many difficulties that manufacturers face in implementing a CIM system. One of these is a shortage of qualified CIM technicians and engineers.

Manufacturers have great need for graduates who understand CIM and the integration of all the elements of a CIM system. This need in Southeast Georgia is being addressed by Georgia Southern University (GSU). A course /laboratory in CIM system at GSU provides an industriallevel training in an educational environment.

CIM philosophy has been defined in a variety of ways for decades. It also means different things to different industries [1]. Overall the best definition suggests that a complete CIM system exists when all automated physical activities and automated information processing activities are integrated [2]. Using a network database, a CIM system can manage all manufacturing activities and collect production data that can be used to optimize productivity [3-4]. Although it may not be quite practical or economically feasible for all companies ever fully to achieve a complete CIM system, manufacturers realize that they have to automate in order to achieve a competitive advantage in the global market [5]. The companies that are able to achieve a complete CIM system will benefit significantly in this very competitive world markets $\left.{ }_{[6}\right]$. CIM provides many advantages, a few of these are mentioned in the following. Computer integration of information gives all departments of a factory rapid access to the same production data. Accessibility of production data results in faster response to change, which in turn shortens lead times, increases the company's responsiveness to customer demands, and improves due-date reliability. A computer aided scheduling program helps optimize use of the shop floor, which improves utilization of machine tools and reduces work-in-progress and lead times. Real-time production data can be used to optimize production processes to improve quality, using techniques such as statistical process control. Computer analysis and prediction of material requirements for production can reduce inventory levels and lead times. Integration with suppliers and customers can provide even greater benefits. Downloading machining instructions, including tool changes, from CAM (Computer Aided Manufacturing) systems to CNC (Computer Numerically Controlled) machines reduces machine setup time and increases machine utilization. There are, 
also many arguments that can be made against automation in general and particularly against integrated automation such as CIM [7]. Most of these arguments though are based on the sociological effects of automation and not based on sound economic principles.

If Mechanical Engineering Technology (MET) graduates are to be successful in the job market, considering the recent economic downturn, it is imperative that they have a practical knowledge of automation, production, and CIM systems. The MET program at Georgia Southern University has three areas of emphasis, one of which is materials/manufacturing. One course in this area is Automation and Computer Integrated Manufacturing Systems (CIMS). This course utilizes a laboratory which was initially funded by the National Science Foundation (NSF) in 1992 [8]. Due to significant advances in computer software and hardware, the technology has changed dramatically since 1992. In response to these changes the CIMS laboratory at GSU was recently upgraded. This teaching laboratory is an integral part of the Automation \& CIMS course. The laboratory allows students to gain hands-on experience with a state of art mini-CIM system. Our intention at GSU is to provide students with an understanding of the CIMS philosophy and how machine, computer hardware, and software can work in orchestration to produce a product in a hands-off manufacturing environment. It is our belief that students are empowered by such knowledge and experience in a mechanical/ manufacturing type position. This allows our engineering technology (ET) graduates to function as a true engineering technologists. This paper includes a description of the upgraded CIM system and a sample laboratory activity in the automation and CIM system course at GSU.

\section{The upgraded mini-CIM system at GSU}

The system can be used to produce a part or product in a hands-off manufacturing environment. The system (Figure 1) includes a bench-top three-axis CNC machine and controller, two six-axis robots with controllers, a conveyor with two stations and loading/ unloading pallets, three Local Areas Networked (LAN) computers, a PLC which controls conveyer stations, a feeder, and a storage system. In addition to these components the system has software including CAD/CAM programs, $\mathrm{CNC}$ machine control programs, and the CIM software which integrates all the automated physical and automated information processing activities necessary for production of a part or a product. The system uses a sophisticated network of PCs which allows various devices to perform multiple operations simultaneously. This network also allows CIM devices to communicate with each other. The CIM software allows for targeted training at a given station or device. A utility program allows access to nine types of predefined reports and gives the option of creating a user-defined report. The CIM software uses the latest object oriented techniques in defining the CIM layout, an object's properties, graphic production tracking, and uses graphic objects to simulate CIM operation on a screen. The system allows a user to run a production simulator on a PC to observe results without actually operating the CIM production line. It provides the opportunity to observe how a set of diverse hardware components work together in a real-world environment.

"Proceedings of the 2003 American Society for Engineering Education Annual Conference \& Exposition Copyright 2003, American Society for Engineering Education" 


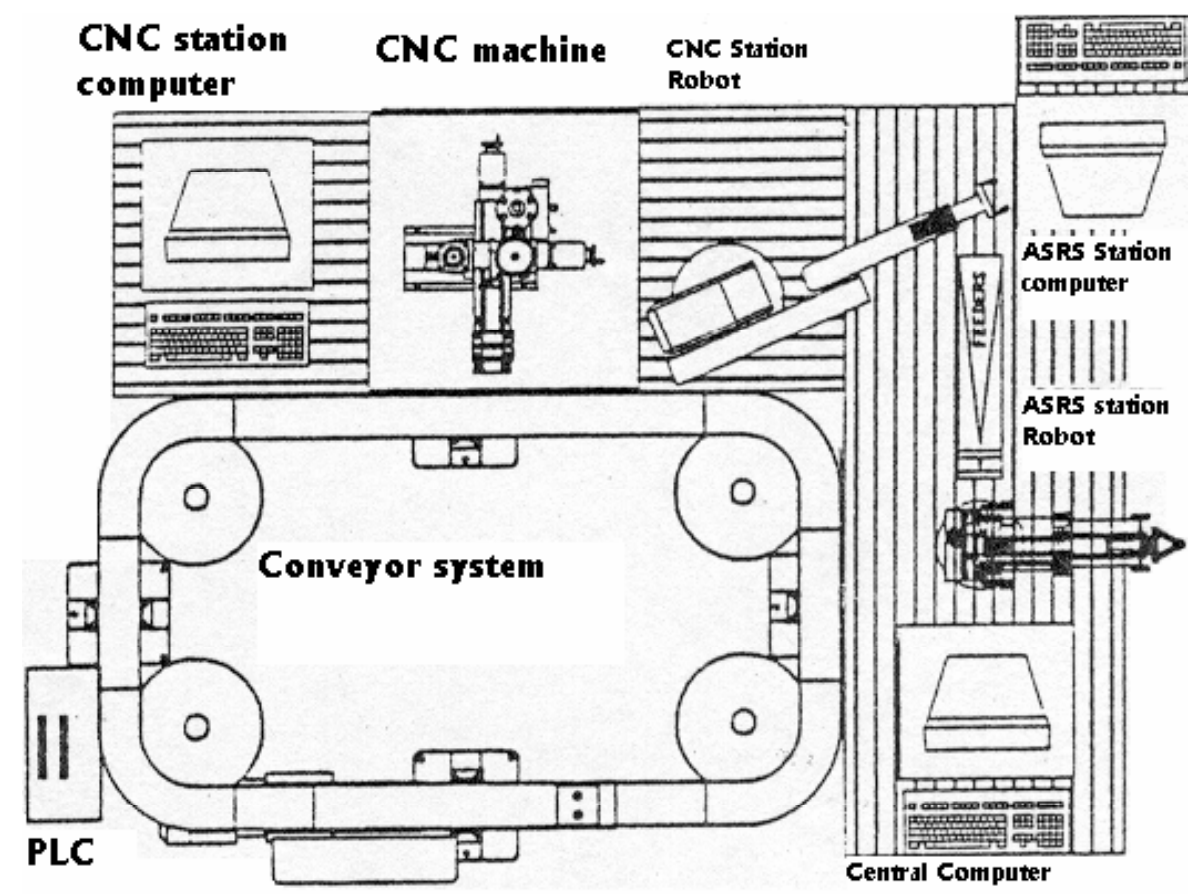

Figure1. Schematic layout of GSU CIM system

The following operations are generally performed in this CIM cell when producing a product:

1. Raw materials are loaded into a feeder at the Automatic Storage and Retrievals System (ASRS) station.

2. Manufacturing orders are generated using the CIM manager software based on prior inputs.

3. Parts are removed by the robot (ER V) at ASRS station from the feeder and transported on the conveyor to production stations.

4. The robot (ER VII) at CNC station takes each part from the conveyor and load the CNC machine.

5. ER VII unloads processed parts to the conveyor for transportation to the next station.

6. ER V removes each finished product from the conveyor to a storage system.

\section{The automation and CIM system course / laboratory:}

In this course students learn concepts in various topics including production automation, mathematical modeling of production, industrial robots applications and programming, NC programming and machining, computer integrated manufacturing systems, and flexible manufacturing systems. Students study robotics and CNC machining and manual programming in the lecture part of the course before using these skills in the laboratory. In the laboratory students work with each component of the system individually and finally with the system as a whole. A 
typical laboratory experience starts with students using the AutoCAD or Pro- Engineer solid modeler to design and produce a drawing of a part to be produced using the CNC machine. They then use a CAM software to determine the tool path, to select proper tool and machining process, and to generate the NC Code. The CAM software also allows them to simulate the machining process and insure correct tool paths prior to actual machining. This verification process also allows students to edit the NC code. Once an NC Code is generated, a dry-run is performed before actually machining the part. Upon completion of this process students input appropriate data for their designed part in the CIM system so that it can be produced in a completely automated fashion using the complete CIM system. Students may also run orders of a soft variety of products.

When students work with the CIM software, they also learn how to operate the CIM system. This requires complete familiarity with all hardware and software of the system. Students use virtual CIM software to simulate a complete manufacturing environment. The software offers a simulation mode in which different production strategies can be tested without actually operating the CIM equipment. This allows students to search for optimal production techniques by experimenting with different production methods. The CIM software provides a realistic, expandable environment through interfaces to hardware including CNC machines, robots, and peripheral equipment. Students learn first-hand how other disciplines such as Production Scheduling, Manufacturing Resource Planning (MRP), Order Entry Systems, and Database Management Systems can be used to optimize the production process. The CIM system is essential in teaching the students the fundamentals of automated production using robotics, computers, and CNC machines.

\section{Sample laboratory activity}

The purpose of this laboratory activity is to familiarize students with the CIM system. They learn how to generate an NC code manually or by using CAD/CAM. Students also learn about the general set up and operation of the mini-CIM system.

A sample CIM application, production of a part, is used to demonstrate the general concepts of the CIM system to students. The steps necessary to complete the laboratory exercise are explained in more detail in a handout provided to students. In this sample application students produce a simple cavity in a small solid cube. The following steps detail the process of making the part. Students either write the NC program manually or first use a CAD program to produce a drawing of a part and then a CAM program to generate the NC code. Upon the completion of this process students use the CIM program to prepare the system for production. The program allows our students to define machines and their associated production processes. They also input the part definitions, storage definitions, MRP, customer orders, and manufacturing orders. Once the system is set up, students run the CIM software in simulation mode to ensure that everything is working correctly, they then run the system in real mode. The following events will take place during the production of the part:

"Proceedings of the 2003 American Society for Engineering Education Annual Conference \& Exposition Copyright 2003, American Society for Engineering Education" 
The ASRS robot takes a solid cube from the feeder, places it on a pallet, and places the pallet on the conveyor. When the cube arrives at the CNC station, the CNC robot loads the cube into the milling machine. The CNC milling machine reams out the center of the cube to form the part. Upon completion of machining process the robot (ER VII) at the CNC station unloads the part onto the conveyor. When the part arrives at the ASRS station, the robot (ER V) places the finished product in a storage cell. This process is repeated for each parts requested in an order. Students generally run mixed orders of a variety of parts. Meanwhile production data is collected on every aspect of the operation and stored in a database. This data might include the numbers of raw material available, the number of completed parts, parts in process and their locations at any time, time of actual machining, and more. The data can then be used for process improvement.

\section{Concluding remarks}

This course / laboratory has been very well received by students and regional industry. A survey of graduates indicates that they have been able to use the knowledge gained in the automation and CIM system course in their activities in manufacturing environments. Surveys of employers and comments from industrial advisory committee members also indicate that these concepts are very valuable to industry. We are continually improving this laboratory and integrate the knowledge gained in this course further into the MET curriculum.

\section{References:}

1. Riley, L. A. And Cox L., "Computer Integrated Manufacturing: Challenges and Barriers to Implementation", The Technology Interface, Winter 1998.

2. Gould L., "CIM is Easier than Ever" , System Integration, December 1989, pp 54 - 59

3. Samadhi, T. and Ari M., Hoang K., "Shared Computer-Integrated Manufacturing for Various Types of Production Environment" , International Journal of Operation \& Production Management, Volume 15, Issue 5, 1995, pp $95-109$

4. Groves C., "Hands Off Manufacturing Transcends Limits of CIM" , Industrial Engineering, August 1990 pp 29 31

5. Aronson R., "Lead Winners Find CIM is Key to Improvement", Manufacturing Engineering, Volume 115, Issue 5, November 1995, pp $3-69$

6. Vanfossen R., "Automation A Must for Industrial Survival" , Automation, Volume 37, December 1990, pp 41

7. Davoud, M.S., "The Technology of Automation and its Effect on the Society" , Humanities and Technology Association Review, Volume 12, pp 12 - 25, Fall 1993.

8. Wang, J. H., and Davoud, M. S., "Incorporating a Computer Integrated Manufacturing Laboratory Into an

"Proceedings of the 2003 American Society for Engineering Education Annual Conference \& Exposition Copyright 2003, American Society for Engineering Education" 
Engineering Technology Curriculum", 1993 ASEE Annual Conference Proceedings, pp 1308 - 1311.

\section{Biographical Information}

\section{MOHAMMAD S. DAVOUD}

Dr. Davoud is currently a professor and coordinator of the mechanical engineering technology program at Georgia Southern University. He holds Bachelor, Master and Ph.D. degrees in Mechanical Engineering and is a Registered Professional Engineer in Georgia. He is currently teaching courses in materials, manufacturing processes, and computer integrated manufacturing system. Dr. Davoud has conducted research in areas such as mechanism design and automation. His current research is in the area of thermo-mechanical analysis of manufacturing processes. 